\title{
Significantly fast spinodal decomposition and inhomogeneous nanoscale martensitic transformation in Ti-Nb-O alloys
}

\author{
Yuya ISHIGURO* ${ }^{*}$, Yuhki TSUKADA ${ }^{1}$, Toshiyuki KOYAMA ${ }^{1}$ \\ ${ }^{1}$ Department of Materials Design Innovation Engineering, Graduate School of Engineering, Nagoya University, Furo-cho, Chikusa-ku, Nagoya 464-8603, Japan
}

*Corresponding author (first author): Tel.: +81-52-789-3613, E-mail address: ishiguro.yuya@e.mbox.nagoya-u.ac.jp

The $\beta$ phase spinodal decomposition during continuous cooling in $\mathrm{Ti}-\mathrm{Nb}-\mathrm{O}$ alloys is investigated by the phase-field method. Addition of only a few at. $\% \mathrm{O}$ to $\mathrm{Ti}-23 \mathrm{Nb}$ (at.\%) alloy remarkably increases the driving force of the $\beta$ phase spinodal decomposition. During isothermal heat treatment at $1000 \mathrm{~K}$ and $1100 \mathrm{~K}$ in $\mathrm{Ti}-23 \mathrm{Nb}-3 \mathrm{O}$ (at.\%) alloy, the $\beta$ phase separates into $\beta_{1}$ phase denoted as $(\mathrm{Ti})_{1}(\mathrm{O}, \mathrm{Va})_{3}$ and $\beta_{2}$ phase denoted as $(\mathrm{Ti}, \mathrm{Nb})_{1}(\mathrm{Va})_{3}$, resulting in the formation of nanoscale concentration modulation. The phase decomposition progresses in $0.3-20 \mathrm{~ms}$. In Ti-23Nb-XO alloys $(X=1.0,1.2,2.0)$, the spinodal decomposition occurs during continuous cooling with the rate of $500 \mathrm{~K} \mathrm{~s}^{-1}$, indicating that the spinodal decomposition occurs during water quenching in the alloys. It is assumed that there is a threshold value of oxygen composition for inducing the spinodal decomposition because it does not occur during continuous cooling in Ti-23Nb-0.6O (at.\%) alloy. The concentration modulation introduced by the $\beta$ phase decomposition has significant effect on the $\beta \rightarrow \alpha$ " martensitic transformation. Hence, it seems that for controlling microstructure and mechanical properties of Ti-Nb$\mathrm{O}$ alloys, careful control of heat treatment temperature and cooling rate condition is required.

\section{Introduction}

Some $\beta$-type $\mathrm{Ti}-\mathrm{Nb}$ alloys have shape-memory and superelasticity properties and are applied to biomedical materials [1-3]. The shape-memory and superelasticity properties of the alloys are derived from the martensitic transformation (MT) from the $\beta$ phase (with a body-centered cubic lattice) to the $\alpha$ " phase (with a face-centered orthorhombic lattice). Miyazaki et al. have reported that in oxygen added Ti-Nb alloys, the long-range MT is suppressed and the nanoscale lattice-modulated domain is formed instead, which is called nanodomain [4-8]. In general, the oxygen is known as a typical $\alpha$-stabilizing element and its addition to Ti-based alloys is assumed to promote the MT from the $\beta$ phase to the $\alpha$ " phase (or $\alpha$ ' phase with a hexagonal lattice). Hence, effects of the oxygen addition on the MT and the nanodomain formation have long been unclear $[6,7,9]$.

In a previous phase-field simulation study, we proposed that the nanodomain formation can be explained by the diffusional-displacive transformation [10]. The oxygen addition to a Ti-Nb alloy promotes the nanoscale spinodal decomposition of the $\beta$ phase into Nb-lean $\beta_{1}$ phase and Nb-rich $\beta_{2}$ phase at $1073 \mathrm{~K}$ or $1173 \mathrm{~K}$, which are typical homogenization temperatures of Ti-Nb-based alloys. Because of the difference of Nb concentration between the $\beta_{1}$ and $\beta_{2}$ phases, the selective $\beta_{1} \rightarrow \alpha$ " MT occurs at $300 \mathrm{~K}$, resulting in the nanodomain formation.

The phase separation occurs in Ti-Ta [11], Ti-Mo [12] and Ti-Nb alloys [13]. In Ti-Nb binary system, the $\beta$ phase separation region does not exist in the equilibrium phase diagram but it appears in the metastable phase diagram considering only the $\beta$ and $\omega$ phases [14]. The spinodal decomposition in Ti-Nb-based alloys has been observed experimentally in a $\mathrm{Ti}-\mathrm{Nb}-\mathrm{Ta}-\mathrm{Zr}$ alloy via three-dimensional atom-probe tomography $[15,16]$. It has been suggested that the MT behavior and mechanical properties of the alloy can be influenced by the concentration modulation of $\mathrm{Ti}$ and $\mathrm{Nb}$ introduced by the spinodal decomposition [17]. Therefore, the precise knowledge about the $\beta$ phase spinodal decomposition in Ti-Nb-based alloys is necessary to control the mechanical properties of the alloys.

In this study, the $\beta$ phase spinodal decomposition in $\mathrm{Ti}-\mathrm{Nb}-\mathrm{O}$ alloys during water quenching is investigated by the phase-field method. In the calculation of the total free energy of the system, the Gibbs energy and the gradient energy are considered. The Gibbs energy is formulated based on the CALPHAD method [18] and the thermodynamic parameters of the phase diagram of the $\mathrm{Ti}-\mathrm{Nb}-\mathrm{O}$ system are used. In order to discuss the time scale of the simulation quantitatively, the diffusion mobility is related to the experimental data on the diffusion coefficients of $\mathrm{Nb}$ and $\mathrm{O}$ in $\beta$-type Ti-based alloys.

\section{$\underline{\text { 2. Calculation method }}$}

The field variable $z_{X}(\mathbf{r}, t)$ is defined using the mole fraction $x_{X}(\mathbf{r}, t)$ as follows [19]:

$$
z_{X}(\mathbf{r}, t)=\frac{x_{X}(\mathbf{r}, t)}{1-x_{\mathrm{O}}(\mathbf{r}, t)},(X=\mathrm{Ti}, \mathrm{Nb}, \mathrm{O})_{,(1)}
$$

where $X$ denotes the components $(X=\mathrm{Ti}, \mathrm{Nb}, \mathrm{O})$, and $\mathbf{r}$ and $t$ denote positional vector and time, respectively. The $z_{\mathrm{Nb}}(\mathbf{r}, t)$ and $z_{\mathrm{O}}(\mathbf{r}, t)$ are regarded as independent variables, and their temporal evolution is calculated by the Cahn-Hilliard equation as follows [20]:

$$
\frac{\partial z_{X}(\mathbf{r}, t)}{\partial t}=\nabla \cdot\left[M_{X} \nabla\left(\frac{\delta G_{\mathrm{sys}}}{\delta z_{X}(\mathbf{r}, t)}\right)\right]_{(2)}
$$

where $G_{\text {sys }}$ is the total free energy of the system, and $M_{X}$ is the diffusion mobility of the component $X$. The $G_{\text {sys }}$ is defined by

$$
G_{\mathrm{sys}}=\int_{\mathbf{r}}\left\{G_{\mathrm{c}}^{\beta}+\sum_{X=\mathrm{Ti}, \mathrm{Nb}, \mathrm{O}} \frac{\kappa_{z}}{2}\left(\nabla z_{X}\right)^{2}\right\} \mathrm{d} \mathbf{r}
$$

where $G_{\mathrm{c}}{ }^{\beta}$ is the Gibbs energy of the $\beta$ phase and $\kappa_{z}$ is the gradient energy coefficient. For simplicity, the values of $\kappa_{z}$ for all components are assumed to be identical. Based on the CALPHAD method, the $G_{\mathrm{c}}{ }^{\beta}$ is formulated using the two-sublattice model [18], $(\mathrm{Nb}, \mathrm{Ti})_{1}(\mathrm{O}, \mathrm{Va})_{3}$, where Va denotes the vacancy. The thermodynamic parameters of the phase diagram of the Ti-Nb-O system are used [21-24]. The $M_{X}$ is related to the impurity diffusion coefficient, $D_{\mathrm{Nb}}$ or $D_{\mathrm{O}}$ [19,25]:

In this study, one-dimensional simulation was performed for the length scale of $20 \mathrm{~nm}$ by using 64 computational grids, and the periodic boundary condition was assumed. The Cahn-Hilliard equation (Eq. (2)) was solved by the conventional finite difference method with explicit Euler technique. In the simulation under the water quenching condition, the temperature was decreased from $1200 \mathrm{~K}$ to $300 \mathrm{~K}$ with the cooling rate of $500 \mathrm{~K} \mathrm{~s}^{-1}$. The simulation condition is schematically shown in Fig. 1 .

(C) The Authors, published by EDP Sciences. This is an open access article distributed under the terms of the Creative Commons Attribution License 4.0 (http://creativecommons.org/licenses/by/4.0/). 


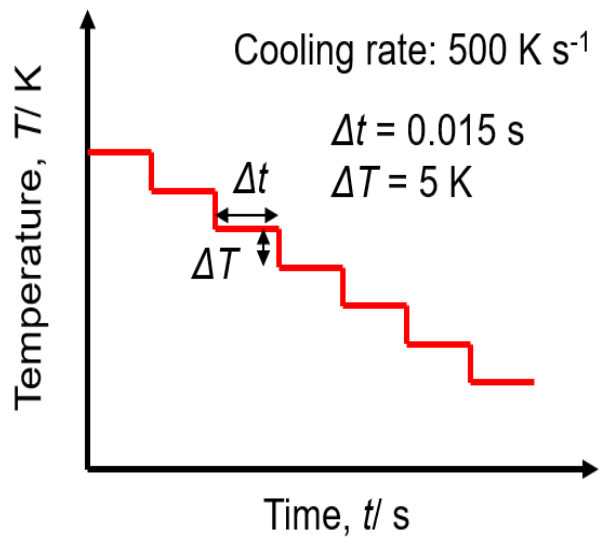

Fig. 1 Schematic representation of the simulation condition of continuous cooling with the rate of $500 \mathrm{~K} \mathrm{~s}^{-1}$.

\section{Results and discussion}

The $\beta$ phase separations in Ti-23Nb-3O (at.\%) alloy during isothermal heat treatments are calculated and the results are shown in Fig. 2. Fig. $2 \mathrm{a}$ and $2 \mathrm{~b}$ show the simulation results at $1100 \mathrm{~K}$ and $1000 \mathrm{~K}$, respectively. At both temperatures, the $\beta$ phase separates into Nb-lean $\beta_{1}$ phase and Nb-rich $\beta_{2}$ phase. The composition of the $\beta_{1}$ phase is Nblean, Ti-rich and O-rich, while that of the $\beta_{2}$ phase is $\mathrm{Nb}$-rich and O-lean. Using the sublattice model, the $\beta_{1}$ and $\beta_{2}$ phases can be expressed as (Ti) $(\mathrm{O} \text {, Va) })_{3}$ and $(\mathrm{Nb}$, $\mathrm{Ti})_{1}(\mathrm{Va})_{3}$, respectively. The concentration modulation is introduced by the spinodal decomposition in $0.3 \mathrm{~ms}$ at $1100 \mathrm{~K}$ and in $1.0 \mathrm{~ms}$ at $1000 \mathrm{~K}$. The compositional difference between the $\beta_{1}$ and $\beta_{2}$ phases and the wave length of the concentration modulation increase with time. It is seen that the compositional difference between the $\beta_{1}$ and $\beta_{2}$ phases at $1000 \mathrm{~K}$ is slightly larger than that at $1100 \mathrm{~K}$, and the spinodal decomposition at $1000 \mathrm{~K}$ takes more time than that at $1100 \mathrm{~K}$. The calculation results show that in Ti$23 \mathrm{Nb}-3 \mathrm{O}$ (at.\%) alloy, the $\beta$ phase spinodal decomposition progresses in $0.3-20 \mathrm{~ms}$ at $1000-1100 \mathrm{~K}$ during the cooling process. When the alloy is water quenched with the cooling rate of $500 \mathrm{~K} \mathrm{~s}^{-1}$, the decrement of $100 \mathrm{~K}$ takes $0.2 \mathrm{~s}$, implying that the spinodal decomposition can occur at $1000-1100 \mathrm{~K}$. The atomic diffusion during water quenching is often ignored but in $\mathrm{Ti}-\mathrm{Nb}-\mathrm{O}$ alloys, it is presumed that the $\beta$ phase spinodal decomposition occurs even during water quenching.

(a)
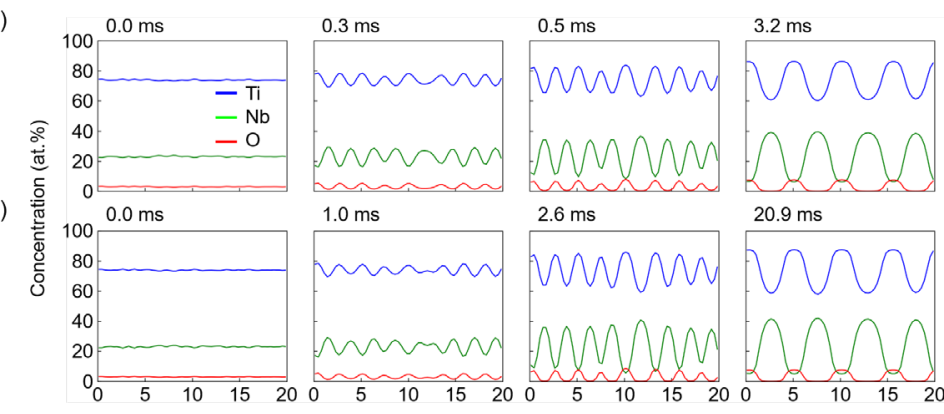

$1.0 \mathrm{~ms}$

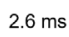

$20.9 \mathrm{~ms}$

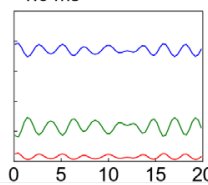

$2.6 \mathrm{~ms}$

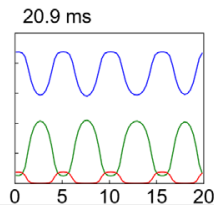

Distance $(\mathrm{nm})$

Fig. 2 Simulation results of spinodal decomposition during isothermal heat treatment in Ti-23Nb-3O (at.\%) alloy; (a) $1100 \mathrm{~K}$ and (b) $1000 \mathrm{~K}$.

In order to investigate the spinodal decomposition behavior during water quenching, the phase-field simulation was performed under the continuous cooling condition with the cooling rate of $500 \mathrm{~K} \mathrm{~s}^{-1}$. Figure 3 shows the change in the concentration profile during the continuous cooling in $\mathrm{Ti}-23 \mathrm{Nb}-1 \mathrm{O}$ alloy. The concentrations of all components are homogeneous at $1200 \mathrm{~K}$ and $1100 \mathrm{~K}$, and the concentration modulation is observed at temperatures below $1000 \mathrm{~K}$. The $\beta$ phase spinodal decomposition progresses at $1100-800 \mathrm{~K}$, and the concentration profile at $800-300 \mathrm{~K}$ undergoes very little change.
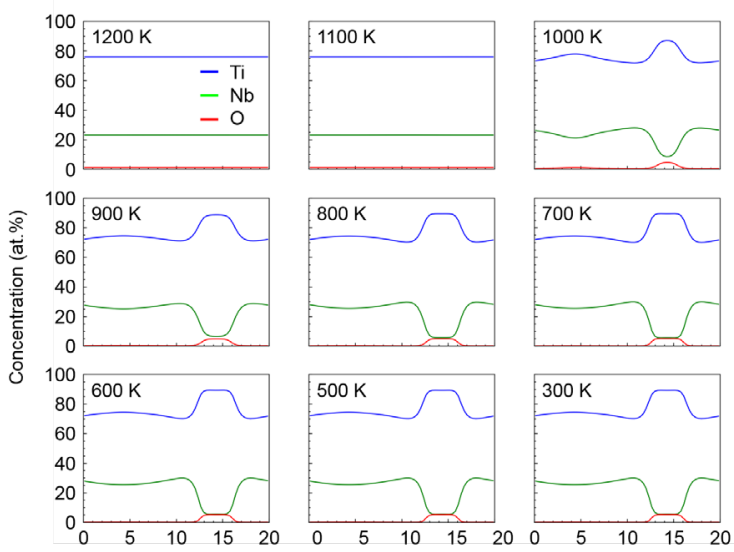

Distance $(\mathrm{nm})$

Fig. 3 Simulation result of the change in the concentration profile under the continuous cooling condition with the cooling rate of $500 \mathrm{~K} \mathrm{~s}{ }^{-1}$ in $\mathrm{Ti}-23 \mathrm{Nb}-1 \mathrm{O}$ alloy.

Figure 4 shows the partial longitudinal section of the metastable phase diagram considering only the $\beta$ phase in Ti-Nb-O system. In the figure, the Nb composition is fixed to $23 \mathrm{at} . \%$ and the spinodal line is shown by the dashed line. The temperature of the binodal line increases from about $700 \mathrm{~K}(\mathrm{Ti}-23 \mathrm{Nb})$ to $1150 \mathrm{~K}$ ( $\mathrm{Ti}-23 \mathrm{Nb}-1 \mathrm{O})$ and to 
above $1400 \mathrm{~K}(\mathrm{Ti}-23 \mathrm{Nb}-2 \mathrm{O})$ with increasing $\mathrm{O}$ composition, indicating that the addition of a few at.\%O to Ti-23Nb alloy induces the $\beta$ phase decomposition. We see from Fig. 4 that the three-phase region exists at $670-790 \mathrm{~K}$. The calculation results of compositions and fractions of the three $\beta$ phases in Ti-23Nb-1O alloy are shown in Fig. 5a and $5 \mathrm{~b}$, respectively. In this study, Nb-rich phase that appears at temperatures below $750 \mathrm{~K}$ is called as $\beta_{2}$ ' phase. With decreasing temperature, the $\beta_{2}$ ' phase appears at about $750 \mathrm{~K}$ and the $\beta_{2}$ phase disappears at $670 \mathrm{~K}$. Compared to the $\beta_{1}$ phase, both $\beta_{2}$ and $\beta_{2}$ ' phases are Nb-rich; however, the compositions of the $\beta_{2}$ and $\beta_{2}$ ' phases are clearly different from each other. The $\beta_{2}$ phase is Ti-Nb-based phase with little oxygen. On the other hand, the $\beta_{2}$ ' phase is Nb-based phase with little oxygen. Using the sublattice model, the $\beta_{1}, \beta_{2}$ and $\beta_{2}$ ' phases can be expressed as $(\mathrm{Ti})_{1}(\mathrm{O}, \mathrm{Va})_{3},(\mathrm{Nb}, \mathrm{Ti})_{1}(\mathrm{Va})_{3}$ and $(\mathrm{Nb})_{1}(\mathrm{Va})_{3}$, respectively. The $\mathrm{O}$ composition of the $\beta_{1}$ phase in the $\beta_{1}+\beta_{2}$ ' region is lower than that in the $\beta_{1}+\beta_{2}$ region (see Fig. 5a), and the fraction of the $\beta_{1}$ phase in the $\beta_{1}+\beta_{2}$ ' region is higher than that in the $\beta_{1}+\beta_{2}$ region (see Fig. 5b). Hence, microstructures that are formed during isothermal heat treatments in the $\beta_{1}+\beta_{2}$ and $\beta_{1}+\beta_{2}$ ' regions would be quite different from each other.

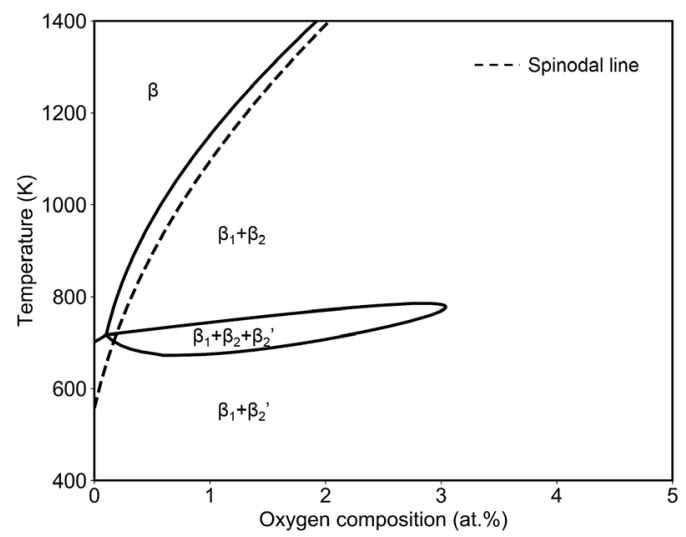

Fig. 4 Calculated partial longitudinal section of the metastable phase diagram considering only the $\beta$ phase. The $\mathrm{Nb}$ composition is fixed to 23 at. $\%$.
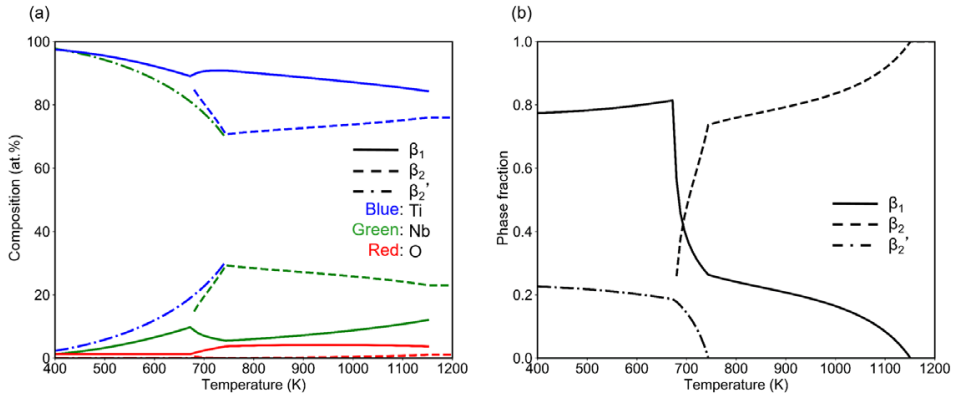

Fig. 5 Calculation results of compositions and fractions of the three $\beta$ phases in Ti-23Nb-1O alloy; (a) temperature dependence of composition and (b) temperature dependence of phase fraction.

Figure 6 shows the change in the concentration distribution during continuous cooling with the rate of $500 \mathrm{~K} \mathrm{~s}^{-1}$ in Ti-23Nb-10 alloy; the concentration data is extracted from the simulation results shown in Fig. 3. In Fig. 6, the tie line is shown by solid line at each temperature. At $700 \mathrm{~K}$, the alloy composition is inside the three-phase region and hence the three-phase triangle is shown instead of the tie line. In Ti-23Nb-1O alloy, the temperature of the spinodal line is $1090 \mathrm{~K}$. However, we see from Fig. 6 that the spinodal decomposition does not occur at $1050 \mathrm{~K}$ during the continuous cooling. The spinodal decomposition progresses at $1050-800 \mathrm{~K}$ along the tie lines. As shown in Fig. 5 , in $\mathrm{Ti}-23 \mathrm{Nb}-1 \mathrm{O}$ alloy, there is the $\beta_{1}+\beta_{2}$ phase region at temperatures above $750 \mathrm{~K}$, while the $\beta_{1}+\beta_{2}$ ' appears at temperatures below $670 \mathrm{~K}$; this is also seen in Fig. 6 because the tie lines at $1050-800 \mathrm{~K}$ and $600-400 \mathrm{~K}$ are clearly different from each other. The concentration distribution slightly changes at $700-400 \mathrm{~K}$ and does not coincide with the tie line of the $\beta_{1}+\beta_{2}$ ' phase. This result indicates that during the continuous cooling, the concentration modulation introduced by the spinodal decomposition at high temperatures is maintained at low temperatures.

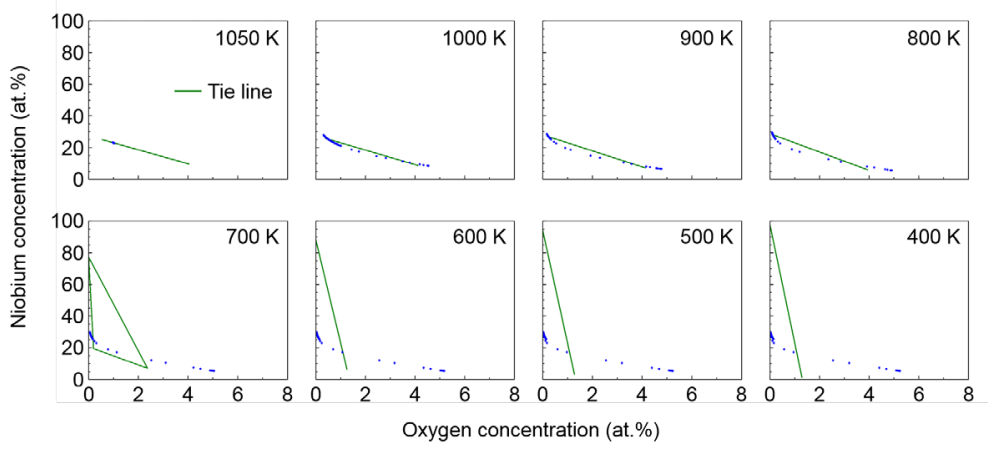

Fig. 6 Change in the concentration distribution during continuous cooling with the rate of $500 \mathrm{~K} \mathrm{~s}^{-1}$ in Ti-23Nb-10 (at.\%) alloy. The concentration data is extracted from the simulation results shown in Fig. 3.

The effect of $\mathrm{O}$ composition of the alloy on the spinodal decomposition behavior during the continuous cooling was investigated by phase-field simulations. Figure 7 shows the change in the concentration profile during continuous cooling with the rate of $500 \mathrm{~K} \mathrm{~s}^{-1}$ in Ti-23Nb-XO alloys $(X=0.6,1.2,2.0)$. The phase decomposition does not occur in $\mathrm{Ti}-23 \mathrm{Nb}-0.6 \mathrm{O}$ alloy, indicating that there is a critical value of $\mathrm{O}$ composition for inducing the spinodal decomposition during water quenching. The concentration 
modulation is observed in $\mathrm{Ti}-23 \mathrm{Nb}-1.2 \mathrm{O}$ alloy at $1100 \mathrm{~K}$, while the spinodal decomposition occurs at $1200 \mathrm{~K}$ in $\mathrm{Ti}-23 \mathrm{Nb}-2.0 \mathrm{O}$ alloy. The spinodal decomposition temperature increases as the $\mathrm{O}$ composition increases.

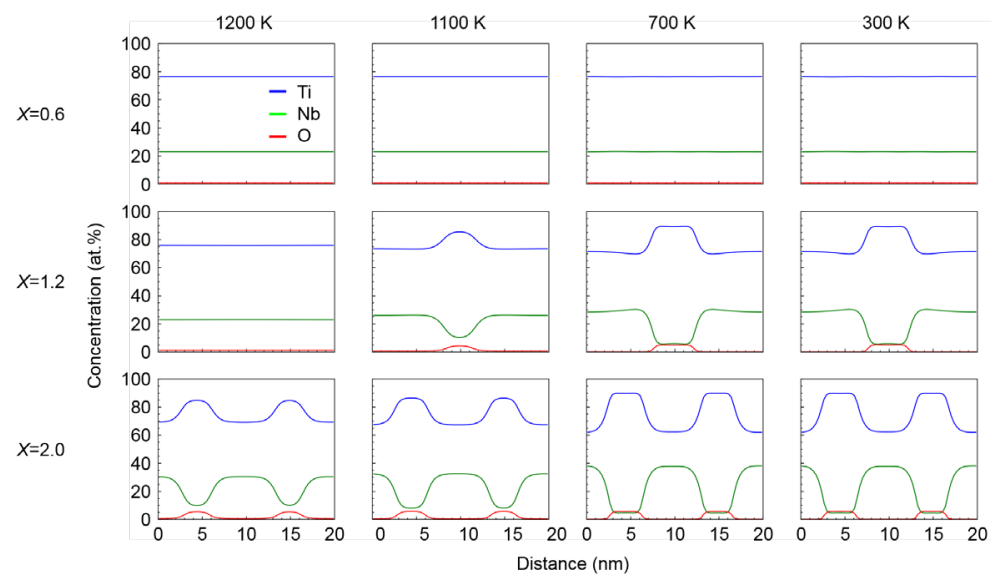

Fig. 7 Change in the concentration profile during continuous cooling with the rate of $500 \mathrm{~K} \mathrm{~s}^{-1}$ in Ti-23Nb-XO (at.\%) alloys $(X=0.6,1.2,2.0)$.

In order to understand the relationship between the $\beta$ phase spinodal decomposition and the $\beta \rightarrow \alpha$ " MT, the driving force of the MT, $\Delta G_{\mathrm{MT}}$, corresponding to the concentration profiles at $300 \mathrm{~K}$ shown in Figs. 3 and 7 was investigated. The $\Delta G_{\mathrm{MT}}$ is defined as $\Delta G_{\mathrm{MT}}=G_{\mathrm{c}}{ }^{{ }^{-}} G_{\mathrm{c}}{ }^{\alpha "}$; the $\alpha$ " phase is more stable than the $\beta$ phase when $\Delta G_{\mathrm{MT}}>0$, while the $\beta$ phase is more stable than the $\alpha$ " phase when $\Delta G_{\mathrm{MT}}<0$. In our calculation, because of the lack of experimental data, the Gibbs energy of the $\alpha$ phase $\left(G_{\mathrm{c}}{ }^{\alpha}\right)$ is used instead of $G_{\mathrm{c}}{ }^{\alpha}$." The concentration profiles of Ti-23Nb-XO alloys $(X=1.0,1.2,2.0)$ and the corresponding $\Delta G_{\mathrm{MT}}$ profiles are shown in Fig. 8a and $8 \mathrm{~b}$, respectively. In Ti-23Nb-1.0O and Ti-23Nb-1.2O alloys, $\Delta G_{\mathrm{MT}}>0$ in the entire region. However, the $\beta$ phase stability in the Nb-rich region ( $\beta_{2}$ phase) is extremely higher than that in the Nb-lean region ( $\beta_{1}$ phase). This is due to the fact that $\mathrm{Nb}$ is one of the typical $\beta$-stabilizing elements. In Ti-23Nb-2.0O alloy, nanoscale distribution of the $\alpha$ " phase stable region $\left(\Delta G_{\mathrm{MT}}>0\right)$ and the $\beta$ phase stable region $\left(\Delta G_{\mathrm{MT}}<0\right)$ can be seen. Note that $\Delta G_{\mathrm{MT}}$ is not so influenced by the average composition of the alloy (see dashdot line in Fig. 8b) but rather is influenced by the degree of the concentration modulation introduced during water quenching. Therefore, careful design of heat treatment and cooling rate conditions is assumed to be necessary to control the $\beta \rightarrow \alpha$ " MT behavior and the mechanical properties of Ti-Nb-O alloys.

(a)

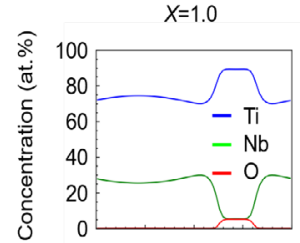

(b)

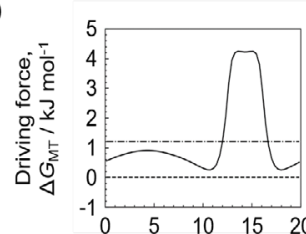

$x=1.2$
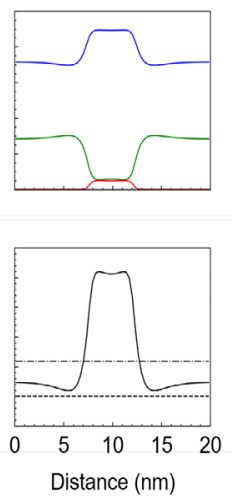

$x=2.0$
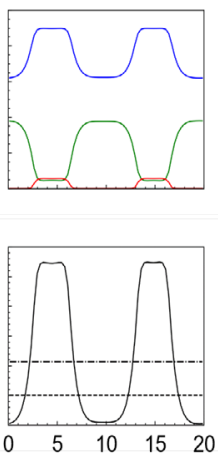

$-\Delta G_{M T}$

$-\cdot \Delta G_{M T}$ for average composition

$--\Delta G_{M T}=0 \mathrm{~kJ} \mathrm{~mol}^{-1}$

Fig. 8 (a) concentration profiles of Ti-23Nb-XO (at.\%) alloys $(X=1.0,1.2,2.0)$ after the continuous cooling from $1200 \mathrm{~K}$ to $300 \mathrm{~K}$ with the rate of $500 \mathrm{~K} \mathrm{~s}{ }^{-1}$ and (b) driving force of $\beta \rightarrow \alpha$ " martensitic transformation, $\Delta G_{\mathrm{MT}}$, corresponding to the concentration profiles shown in (a).

\section{Conclusions}

The $\beta$ phase spinodal decomposition during continuous cooling in $\mathrm{Ti}-\mathrm{Nb}-\mathrm{O}$ alloys was investigated by the phase-field method. The obtained results are as follows.

(1) Oxygen addition to the alloy promotes the $\beta$ phase spinodal decomposition to Nb-rich and Nb-lean phases. In Ti-23Nb-3O (at.\%) alloy, the $\beta$ phase separates into the nanoscale $\beta_{1}$ and $\beta_{2}$ phases that can be expressed as $(\mathrm{Ti})_{1}(\mathrm{O}, \mathrm{Va})_{3}$ and $(\mathrm{Nb}, \mathrm{Ti})_{1}(\mathrm{Va})_{3}$, respectively, during isothermal heat treatment at $1100 \mathrm{~K}$ and $1000 \mathrm{~K}$. The spinodal decomposition progresses in $0.3-20 \mathrm{~ms}$ at $1000-1100 \mathrm{~K}$.

(2) In Ti-23Nb-XO alloys $(X=0.1-3.0)$, the three-phase region of the $\beta_{1}, \beta_{2}$ and $\beta_{2}$ ' phases exists at $670-790 \mathrm{~K}$. The $\beta_{2}$ ' phase can be expressed as (Nb) $(\mathrm{Va})_{3}$. In Ti$23 \mathrm{Nb}-1 \mathrm{O}$ alloy, the tie line of the $\beta_{1}+\beta_{2}$ phase at temperatures above $750 \mathrm{~K}$ is clearly different from that of the $\beta_{1}+\beta_{2}$ ' phase at temperatures below $670 \mathrm{~K}$.

(3) The $\beta$ phase spinodal decomposition in oxygen-added Ti-23Nb (at.\%) alloys occurs during continuous cooling with the rate of $500 \mathrm{~K} \mathrm{~s}{ }^{-1}$, indicating that the spinodal decomposition progresses during water quenching. The concentration modulation introduced by the $\beta_{1}+\beta_{2}$ spinodal decomposition at $1050-800 \mathrm{~K}$ is maintained at lower temperatures during the continuous cooling. The $\beta$ phase spinodal decomposition has significant effect on the $\beta \rightarrow \alpha$ " MT. Hence, careful design of heat treatment and cooling rate conditions is assumed to be necessary to control the mechanical properties of $\mathrm{Ti}-\mathrm{Nb}-\mathrm{O}$ alloys.

\section{Acknowledgement}


This work was partly supported by the research grant from Kyosho Hatta Foundation.

\section{References}

[1] M. Niinomi, Metall. Mater. Trans. A 33(3) (2002) 477.

[2] H.Y. Kim, S. Hashimoto, J.I. Kim, et al., Mater. Trans. 45(7) (2004) 2443-2448.

[3] H.Y. Kim, Y. Ikehara, J.I. Kim, et al., Acta Mater. 54(9) (2006) 2419-2429.

[4] J.I. Kim, H.Y. Kim, H. Hosoda, et al., Mater. Trans. 46(4) (2005) 852-857.

[5] Y. Nii, T.-h. Arima, H.Y. Kim, et al., Phys. Rev. B 82(21) (2010) 214104.

[6] M. Tahara, H.Y. Kim, T. Inamura, et al., Acta Mater. 59(16) (2011) 6208-6218.

[7] M. Tahara, T. Kanaya, H.Y. Kim, et al., Acta Mater. 80 (2014) 317-326.

[8] M. Tahara, T. Inamura, H.Y. Kim, et al., Scripta Mater. 112 (2016) 15-18.

[9] J.G. Niu, W.T. Geng, Acta Mater. 81 (2014) 194-203.

[10] Y. Ishiguro, Y. Tsukada, T. Koyama, Comput. Mater. Sci. 151 (2018) 222-230.

[11] M. Ikeda, S.-y. Komatsu, Y. Nakamura, MATERIALS TRANSACTIONS 45(4) (2004) 1106-1112.

[12] R. Davis, H.M. Flower, D.R.F. West, Acta Metallurgica 27(6) (1979) 1041-1052.

[13] C.R.M. Afonso, P.L. Ferrandini, A.J. Ramirez, et al., Acta Biomater. 6(4) (2010) 1625-1629.

[14] D.L. Moffat, U.R. Kattner, Metall. Trans. A 19(10) (1988) 2389-2397.

[15] H.L. Wang, S.A.A. Shah, Y.L. Hao, et al., J. Alloy. Compd. 700 (2017) 155-158.

[16] Y.L. Hao, H.L. Wang, T. Li, et al., J. Mater. Sci. Technol. 32(8) (2016) 705-709.

[17] J. Zhu, Y. Gao, D. Wang, et al., Acta Mater. 130 (2017) 196-207.

[18] N. Saunders, A.P. Miodownik, CALPHAD : calculation of phase diagrams : a comprehensive guide, Pergamon 1998.

[19] I. Loginova, J. Odqvist, G. Amberg, et al., Acta Mater. 51(5) (2003) 1327-1339.

[20] L.-Q. Chen, Ann. Rev. Mater. Res. 32(1) (2002) 113-140.

[21] B.J. Lee, N. Saunders, Z. Metallkd. 88 (1997) 152-161.

[22] R.J. Pérez, A.R. Massih, J. Nucl. Mater. 360(3) (2007) 242-254.

[23] Y. Zhang, H. Liu, Z. Jin, Calphad 25(2) (2001) 305-317.

[24] A.T. Dinsdale, Calphad 15(4) (1991) 317-425.

[25] The Japan Institute of Metals, Kinzoku data book [Metal's data book], third ed. ed., Maruzen, Tokyo, 1993. 